\title{
A Concept Analysis of Balance
}

Sarah E. Byrne ${ }^{1}$, Laurie Grizzard ${ }^{2}$ and Sharon L. Van Sell ${ }^{3 *}$

${ }^{1}$ Graduate Nursing Program, Texas Woman's University, United States of America

${ }^{2}$ Graduate Nursing Program, Texas Woman's University, United States of America

${ }^{3}$ Professor, The Houston J. and Florence A. Doswell College of Nursing, Texas Woman's University, United States of America

\begin{abstract}
Often used in all medical disciplines, balance has remained undefined as a concept in nursing science. Walker and Avant [1] developed a framework for concept analysis, used in analyzing the concept of balance in advanced practice nursing. The disciplines of physiotherapy and psychology have applied the concept of balance; however, nursing has not incorporated the concept of balance. The analysis of the concept of balance, therefore, included an operating definition and the following defining attributes of balance: (a) the human being; (b) the three parts making up the human being-the noetic, the physical, and the psyche; and (c) homeostasis. The goal of analyzing the concept of balance was for advanced practice nurses to incorporate the concept of balance into patient goals when diagnosing and providing care. Ideally, using the concept should result in optimal health and well-being for patients.
\end{abstract} Publication History:

Received: April 04, 2018

Accepted: June 21, 2018

Published: June 23, 2018

\section{Keywords:}

Balance, Homeostasis, The human being, Optimal function
Advanced practice nurses (APNs) have played a unique role in the healthcare system by offering a more holistic approach than provided by the medical model to diagnosing and caring for patients. This approach has focused on both the patient and his or her environment as a whole and incorporated treatment to encourage optimal wellness and health. The traditional medical model was limiting because physicians emphasized diagnosing only the problem and treating that particular problem. The use of the medical model often resulted in the patient's trading one problem for another. An example of trading one problem for another was prescribing Adderall for a 45 -year-old woman who complained of issues with concentration and focuses without checking her progesterone and estrogen levels, thus potentially creating high blood pressure and sleep disturbances.

Lacking from the medical model and nursing theory is the concept of balance. The need for balance to occur on many levels to obtain optimal health became obvious when diagnosing and caring for patients holistically. Although the concept and the theory of balance exist in physiotherapy and psychology literature, balance has been elusive in nursing science.

\section{Framework for the Concept Analysis}

Walker and Avant [1] defined concept analysis as "a systematic exploration of a concept that determines what a concept is and what it is not" (p. 73). The authors further explained why nurses should have analyzed concepts: "Developing standardized language to describe nursing practice is another primary use of concept analysis" (p. 159) [1]. While many methods were available for concept analysis, Walker and Avant developed an eight-step model that was easiest to understand and was specific to nursing. The eight steps of concept analysis proposed by Walker and Avant included the following: (a) selecting a concept; (b) determining the purpose of the analysis; (c) identifying all uses of the concept; (d) determining the concept's defining attributes; (e) identifying a model case; (f) identifying a borderline case and related, contrary, invented, and illegitimate cases (g) identifying antecedents and consequences of the concept; and (h) defining empirical referents (p. 160) [1]. Walker and Avant's model was the framework employed for this concept analysis of balance.

\section{Theoretical Context and Selection of the Concept}

This concept analysis of balance incorporated several underpinnings. For example, chiropractor John Veltheim [2] referred to the concept of balance in The Science and Philosophy of Bodytalk. Veltheim developed techniques and formulas designed to restore effective dynamic system principles based on the knowledge that if the physician or patient were to restore those factors, the body would heal itself in most cases. The Bodytalk system emanated from a dynamic systems theory based on a 40-year-old scientific model explained by physicist Fritj Capra [3], in his book The Turning Point: Science, Society, and the Rising Culture. Veltheim [2] remarked,

The heart and brain maintain a continuous two-way dialogue; each influencing the other's functioning. The signal the heart sends to the brain can influence perception, emotional processing, and higher cognitive functions. This system and circuitry is viewed by neurocardiology researchers as a "heart-brain." (p. 106).

Veltheim demonstrated success with his techniques worldwide. Using Bodytalk techniques resulted in an overall improvement in function occurring within the entire body, and clarity and focus realized within the mind.

Another underpinning of the concept of balance came from nursing professors and theorists Sharon Van Sell and Ioannis Kalofissudis' [4] complexity integration nursing theory (CINT). Specifically, Van Sell and Kalofissudis contributed the self-observation methodology, which incorporated a balance scale level assessment. The balance scale level assessment introduced the nurse, the human being, and the three components that made up the human being: (a) the noetic, (b) the physical, and (c) the psychic. Van Sell and Kalofissudis [4] proposed:

Self-observation methodology in nursing practice induces a more complete coverage of the kinds of needs that emerge from communication of both systems and interactions, i.e., the Subject

"Corresponding Author: Dr. Sharon L. Van Sell, The Houston J. and Florence A Doswell College of Nursing, 5500 Southwestern Medical Avenue, \#7209, Dallas, Texas, 75235-7299, USA, Tel: 1-864-275-3527, Fax: 214-689-6539; E-mail: svansell@twu.edu

Citation: Byrne SE, Grizzard L, Van Sell SL (2018)A Concept Analysis of Balance. Int J Nurs Clin Pract 5: 281. doi: https://doi.org/10.15344/2394-4978/2018/281

Copyright: (C) 2018 Van Sell et al. This is an open-access article distributed under the terms of the Creative Commons Attribution License, which permits unrestricted use, distribution, and reproduction in any medium, provided the original author and source are credited. 
(Nurse) observes the Object (Human Being) as interconnecting with himself, and the object can be the patient, the Human Being in general, the team, the family, or the society. (p. 78).

CINT went even further to share "a continuous flow of energy among the interconnected components of the Human Being sustains life and drives inherent cycles of life involving observation, development, application and evolution" (p. 79) [4].

Based on the theories of Veltheim [2], Capra [3], and Van Sell and Kalofissudis [4], the authors of the present paper concluded that for optimal health and wellness, a balance must exist between the noetic, physical, and psychic levels of the human being. A transfer of energy must also have occurred in the process of obtaining balance.

\section{Aims of the Concept Analysis}

The purpose of this concept analysis was to define the concept of balance in advanced practice nursing and to provide an operational definition of balance. The analysis of balance had the potential to add to the body of knowledge unique to the advanced nursing profession and to be used in research and theory development [1]. According to Walker and Avant, "If the aim is to construct an operational definition, the next step would be to find a research instrument that accurately reflects the defining attributes of the concept" (p. 172) [1].

\section{Uses of the Concept of Balance}

\section{Literature Search Methods}

A preliminary expanded literature search without limiters revealed that a formal concept analysis of balance had not been published within the nursing domain, thus providing additional support for the need for a formal concept analysis of balance.To better define the concept of balance in advanced practice nursing, a more limited search was performed.Of the 34,616 articles that contained the word "balance," one scholarly paper written on the concept of balance was found within the field of physiotherapy [5]. Psychologist Fritz Heider [6] defined a second use of the word balance and created the theory of balance for the field of psychotherapy. The search was then limited to articles related to balance and nursing, revealing 540 articles that mentioned "balance." The 540 articles were excluded because the researcher did not include a definition for balance.

\section{Definitions}

To explore balance, the individuals performing the concept analysis must first establish what the word has meant from various sources and within disciplines. As a case in point, balance was defined in the Merriam-Webster Online Dictionary (2016) as "a state in which different things occur in equal or proper amounts or have an equal or proper amount of importance" (para. 1) [7]. Added to the definition of balance was "mental and emotional steadiness" (para. 2) [7]. Another definition from the Cambridge Dictionary was "a work of art where all the parts work together and no part is emphasized too much" (para. 1) [8]. Finally, the Oxford Dictionaries defined balance as "mental and emotional stability" (para. 1) and included another definition from the perspective of art: "Balance is harmony of design and proportion" (para. 3) [9].
The field of medicine has demonstrated that the body operates with a desire for balance to achieve optimal function. When parts of the body were not in balance with each other-for example, excessive blood loss from trauma-the body would go into a state of dysfunction. Consequently, even without defining the concept of balance, maintaining balance has been a general goal of medicine.

Psychology has applied Heider's theory of balance [6] to show how people develop relationships with each other and with things in their environment. Heider's balance theory explained that when people see a set of cognitive elements as being a system, then those individuals develop a preference for maintaining a balanced state among these elements. In other words, if people were to feel "out of balance," then they become motivated to restore a position of balance [6]. Heider believed a discomfort with imbalance would increase the strength of the attitude and the overall interest in the matter.

Eastern medicine has emphasized the balance between mind, body, and spirit [10]. Balancing mind, body, and spirit was necessary because without balance, the whole system, the human being, suffered. Eastern medicine reinforced the belief that balance is critical for a healthy and successful life [10].

Physiotherapy defined balance as a complex motor skill and referred to balance as postural control [5]. In physiotherapy, balance was often synonymous with equilibrium and postural control, desired states for the body. Through equilibrium and postural control, the human body would prevent itself from falling or losing balance. Balance in physiotherapy has also been viewed as a prerequisite for functional competence because equilibrium remained vital to the performance of activities of daily living [5]. As a final example, neuroscientist Marjorie Woollacott [11] pointed out that both "good" balance control and the ability to integrate balance adjustments into ongoing voluntary movements was the foundation for independent mobility among older persons. Taken together, these definitions of the concept of balance from a variety of medical disciplines suggested that integrating the concept of balance into advanced nursing practice may likely result in better patient outcomes.

\section{Defining Attributes}

In the context of nursing, defining attributes of the concept of balance included the human being and homeostasis. The human being definition is as "an open system not in equilibrium, but interchanging endless material energy and information with the environment" (p. 40) [4]. According to the complexity integration nursing theory, the human being was explained as "the combination of the psyche, nous and physical" (p. 73) [4]. The human being also possessed several characteristics. One trait aligning with the concept of balance, according to Van Sell and Kalofissudis,was the right of the human to have balance and harmony in all levels of existence. The noetic, also known as the nous, equated to the intellect or the mind. The Institute of Noetic Sciences [12] explained: The nous "is how an individual perceives and interprets his or her environment including beliefs, intentions, attitudes, emotions, and all aspects of his or her subjective experience" (para. 1) [12]. In contrast, the physical part of the human being consisted of the actual structure of the human body, comprised of various inter connecting parts to ensure homeostasis and viability. Additionally, the psychic level of the human being is the spiritual component, not to be confused solely with religious practices. 
According to Collins English Dictionary [13], homeostasis comes from two Greek words-"homeo" meaning similar and "stasis" meaning stable (para. 1-2). Physiologist Walter Bradford Cannon coined the term homeostasis in the 20th century based on Claude Bernard's hypothesis that "an organism must have the capacity to maintain its internal environment to live" [14]. In general, homeostasis was regarded as a characteristic of any given system that seeks to regulate its internal environment to maintain stability and a relatively constant condition of properties. The Collins English Dictionary [13] defined owing to the coordinated response of its parts to any situation or stimulus that would tend to disturb its normal condition or function" (para. 3).

\section{Model case}

According to Walker and Avant [1], a concept analysis must provide several examples of the use of the concept. The first should be a model case demonstrating all defining attributes of the concept (p. 163). The model case of the concept of balance, therefore, incorporated all the following components of the human being in addition to homeostasis: (a) the nous, (b) the physical, and (c) the psyche.

Susan was a 54-year-old APN who worked under a family practice physician at a wellness center that specialized in functional medicine. For 15 years, Susan has been employed in the wellness center on a full-time basis and remains passionate about her practice. Susan's patients adore her. Susan has also had many additional roles to juggle: for example; she is a wife as well as a mother of two teenage girls and one son who attends college. Additionally, Susan precepted graduate students in clinical, gaining experience for APN licensure.

One year ago, while Susan was going through menopause, her 86-year-old mother developed ovarian cancer, and Susan became her mother's primary care provider. The news was devastating to Susan because she and her mothers had a close bond. The stress from all areas of life had accumulated to the point Susan found she was having difficulty sleeping. In addition, she felt anxious and exhausted, and was struggling to focus. As a result, Susan became short-tempered with the staff at work and her family at home. The stress of her mother's illness along with menopause also exacerbated Susan's irritable bowel syndrome (IBS).

At a conference on anti-aging medicine, Susan learned about the philosophy and techniques of bodytalk by Veltheim [2]. Veltheim taught the body is an energy-based system designed to heal itself. Bodytalk enlightened Susan regarding the scientific evidence of the unique connection of the mind to the heart, identified as the body mind. Various stressful situations in life taught Susan that she had the potential to distribute the energy exchange between the mind and the body. These stressors most often resulted in compromised balance, communication, and synchronicity of the body mind system. Utilizing the bodytalk tapping methods restored balance, communication, and synchronicity to the entire body. Further, the science related to bodytalk had been growing in popularity all over the world because of the technique's renowned success in both healthcare and school systems [2].

Susan realized she needed balance on many levels and wanted to incorporate the bodytalk[2] philosophy and techniques into her personal and professional life. In addition to bioidentical hormone replacement therapy, Susan employed the bodytalk method as the homeostasis as "the tendency of a system to maintain internal stability,

first step toward regaining her own health and wellness. The bodytalk method helped Susan find balance within her noetic, her physical, and her psyche self. The hormone replacement therapy balanced her hormones, ridding her of the symptoms of menopause. Susan understood she had obtained balance and was in a better position to interact positively again with her environment: her family, her patients, and her staff. Though Susan's family relied on her income, her husband and children agreed to achieve balance was best for her; therefore, Susan cut back oneday of work each week to care for her mother. Susan also hired a caregiver to assist with her mother's health needs. In addition to completing her daily 5 -minute bodytalk techniques, Susan focused on eating smarter and doing yoga three times a week. Within one month, Susan's IBS had also diminished. Susan was also sleeping better and reported to her husband that she felt calm and less anxious. Susan was present with her mother and could enjoy the time they had remaining. Overall, Susan has positively engaged with her environment once again and enjoyed renewed health and wellness.

Susan realized as a result of achieving homeostasis with her body and her mind, her entire system, not just one part, could function optimally and heal faster. Susan discovered that although she approached taking care of her patients holistically, she failed to realize the importance balance played on all three levels of a human being (the nous, the physical and the psyche). Thus, Susan began incorporating the concept of balance as an end goal for all her patients. Now when Susan treated a client, she made sure to be optimally balanced before she started seeing patients. Then, when Susan assessed her clients, she included all three components of their being regardless of the reason they had come to see her.

For example, one day, Susan saw a patient named Margaret. Margaret was a 44-year-old mother who presented with a blood pressure of 145/100 and complained of a chronic headache, anxiety, depression, difficulty sleeping, low libido, difficulty concentrating and weight gain. Susan spent more than 1 hour doing the assessment and developing a relationship with her new client. She learned Margaret had two teenagers, was going to school full-time for her master's degree, worked part-time, and was having some marriage issues due to her husband's travel schedule. Margaret told Susan she just wanted to feel better. Margaret also shared that hypertension ran in both her mother's and father's family. Lab results showed low estrogen and lack of progesterone production, hypothyroidism, and no testosterone production. Susan explained to Margaret that while the nurse practitioner could easily assist with correcting the imbalances of the body by treating hypertension and the hormonal imbalances, she also wanted to assist Margaret in finding an overall balance by bringing balance to the nous and the psyche.

To that end, Susan educated Margaret on the benefits of balancing each part that makes up the human being and defined the nous, physical, and psyche components for to better understand. Margaret expressed that she understood and agreed to the goal of balance to achieve the optimal function of her entire being. Susan then began prescribing the medications needed to balance the body and invited Margaret to the nutrition and cooking classes taught at the wellness center. In addition, Susan gave Margaret a list of resources for various types of exercise classes, meditation classes, and marriage and family counselors.

Margaret returned to the wellness center three months later. Followup labs showed hormone levels all within normal range. Margaret's weight was down seven pounds, and her blood pressure was 115/78.

Int J Nurs Clin Pract

ISSN: 2394-4978

IJNCP, an open access journal Volume 5. 2018. 281 
Margaret reported to Susan she no longer suffered from chronic headaches and was sleeping eight hours a night and was involved in an exercise plan. Margaret had also incorporated a healthy eating plan for her entire family. Margaret and her husband were doing much better since they started attending as a couple and receiving couples counseling at their church; she also decided to go to school part-time instead of full-time. Margaret was much more positive about life and shared she did not feel depressed or anxious any longer. Margaret reported she was much more aware now of the importance of balance in all areas of her life that included all components of her being and her environment. Margaret told Susan when her body and nous felt balanced, growing in her Christian beliefs and relationship with her God became easier, and she was better able to interact positively with her environment despite stressors such as work, school, her mother's illness and care, and marriage challenges.

\section{Borderline case}

Walker and Avant [1] described "borderline cases [as] those examples or instances that contain most of the defining attributes of the concept being examined but not all of them" (p. 164). The following borderline scenario utilized all attributes of the concept of balance other than the components of the human being and the noetic.

John is a 28-year-old man with cerebral palsy (CP) and severe mental retardation. John typically was light-hearted and joyful, operating at the level of a 2-year-old. John especially enjoyed playing with his 2-year-old niece, Julie. John's mother, Anna, was his fulltime caregiver and noticed John refused to eat, had a temperature of $101.3^{\circ} \mathrm{F}$, was clutching his abdomen, and was not able to participate in play time. His ability to thrive was compromised. Although John did not know he needed help, Anna believed something was seriously wrong, and she took him to the local emergency department (ER) for further investigation.

Tara, an ER nurse practitioner, was working the night that John and Anna came into the ER. Tara had recently lost a close friend and had worked on ways to restore balance within herself. Tara found that by using the self-observation methodology [4], she had found balance within herself and could care for her patients more appropriately. Since Tara had applied the self-observation methodology, she transcended and could fully be in balance and have full self-inner awareness [4]. She also used the self-observation method when diagnosing and caring for patients. Tara understood the existence of interconnectedness between all living things and utilized this phenomenon when treating patients [4].

In the hospital, Tara, his APN, diagnosed John with a bowel obstruction. Tara realized due to John's severe mental retardation; he was unable to understand something was wrong cognitively and to know to seek help. To assist with this challenging patient, Anna answered all the questions for John. Tara realized that John's mind, or nous, could never achieve balance because he was not capable of processing information on the level of an adult due to the $\mathrm{CP}$ and severe mental retardation. John was also physically limited due to the CP. Tara needed to consider that John was even more physically out of balance due to the bowel obstruction and could not thrive unless this was corrected. Further, Tara recognized because of the $\mathrm{CP}$ and severe mental retardation, John would not have balance within his psychic or spiritual side, but he could live a happy life if he reached optimal compensation.
The pain caused by the bowel obstruction hindered John's ability to have a relationship with his environment and those around him, as evidenced by the fact John would not play with his niece, Julie, due to the pain from the bowel obstruction. He could not eat. Tara knew for John to function to the best of his ability, removal of the obstruction needed to occur. Tara's plan of care, therefore, included fixing the obstruction to obtain physical balance and to maximize optimizing both the psychic and the noetic components of John as well as possible so that he could achieve optimal balance and function.

John underwent surgery, successfully resolving the obstruction. Once recovered from surgery, John was back to his normal self: $\mathrm{He}$ was smiling, playing with his niece again, eating, laughing, and no longer grimacing or clutching his abdomen. With the obstruction resolved, John's physical component of the being balanced. His mind and spiritual components, however, would remain out of balance because John lacked the ability to be fully balanced due to the $\mathrm{CP}$ and severe mental retardation with which he was born.

In this scenario, Tara, who was in balance, helped John obtain balance through optimal compensation. Due to the CP and severe mental retardation, John was unable to have optimal function or balance within his mind and psychic levels and was also physically limited; therefore, the goal for John was to function the best he could while living in optimal compensation. After fixing the obstruction, balance restored to John's body. With John's psychic level, without pain, he could go back to his normal spiritual level of functioning.All three components of the human being were back in homeostasis to the best of John's ability.

After John had achieved optimal compensation, he was able to exchange positive energy with others around him and with his environment. John was able to experience health and wellness to the best of his ability. In this borderline case, all attributes existed to provide balance to John, except for the noetic and psychic components of the human being. CP and severe mental retardation did not allow John to achieve optimal balance within the mind and psychic components of his being.

\section{Contrary case}

Walker and Avant [1] considered a contrary case as a clear example of "not the concept" (p. 166). In the following contrary case, no attributes were clear; therefore, no balance was achieved.

Debbie was a 250-pound 30-year-old woman who had poor relationships with her parents and friends and presented with high blood pressure, diabetes, depression, and joint pain. Debbie went to see her APN, Bertha, requesting pain medications and diet pills.

An over worked 48-year-old nurse practitioner at a primary care clinic, Bertha did not have enough hours in the day to spend adequate time with her patients and, quite honestly, did not care to spend more time than necessary with them anyway. Bertha took no time to get to know the patients or to hear about what was going on in their lives aside from the complaint that had brought them in. Similarly, Bertha did not take the time to care for herself, and she had gained several pounds over the last year, had ruined relationships with friends and family, and blamed overwork for all of her misfortunes.

Patient Debbie and APN Bertha met for the first time. Debbie asked directly for pain medications and diet pills. Bertha, who asked no further questions about Debbie's life circumstances, obliged and 
wrote the prescriptions and scheduled a follow-up appointment for three months later.

When Debbie returned for her 3-month follow-up, she had lost only 10 pounds, her HAlc was elevated, and her poor life habits remained unchanged. Debbie was not pursuing a healthy lifestyle, she was not following a healthy diet, and she was not exercising. Debbie was still upset about her current condition and was angry with Bertha for not making her feel better. Consequently, Debbie asked APN Bertha for a different, more potent diet pill, a stronger pain pill to relieve her joint pain, and an antidepressant. Debbie did not engage in conversation with Bertha and became hostile easily. Bertha, who was under even more stress because her manager said she needed to see five additional patients a day, simply gave in to Bertha and prescribed the medications requested.

Neither of these women lived life in balance or homeostasis. Bertha had no internal balance because she had not taken the time to be physically in balance by eating a healthy diet or exercising. Due to her work load, Bertha had not tried to keep positive relationships with her friends and family, which affected her noetic component. Third, because Bertha was unhappy and exhausted all the time, she had not made any effort to work on her psychic component; therefore, Bertha had no homeostasis within and could not properly recognize balance or imbalance in her patients.

Also clear in this contrary case scenario was that Debbie had no desire for health or wellness, and she did not want to form relationships. Balance was not going to occur with this patient because Debbie did not wish to have a real relationship with herself or her environment. Further, depression and stress led to additional decline in Debbie's health. Balance did not occur for Debbie because her healthcare provider, Bertha, was also out of balance. Bertha did not recognize or help Debbie with her true problems due to Bertha's own imbalance. Bertha defaulted to treating all patients using the traditional, linear medical model because of her internal struggles and failure to recognize her need for balance to the detriment of patient outcomes.

\section{Antecedents, Consequences, and Operational Definition of Balance}

The following three antecedents appeared with the concept of balance: (a) knowledge, (b) relationship, and (c) energy. Before balance can occur, the APN must have obtained the knowledge and awareness of the patient's situation that is causing imbalance or that a dysfunction exists within the patient's environment. The second antecedent of the concept of balance, relationship, required the APN to have relationships with himself or herself and then to desire to develop a relationship with the patient to assess and participate in helping the patient restore balance and achieve optimal function. The human being, the patient, must recognize the evidence of the imbalance and then want to participate in a relationship with the APN to help restore health and well-being. That interrelationship or interconnectedness, suggested by Van Sell and Kalofissudis [4] and others, expected the APN to develop personal and professional relationships as a part of restoring systemic balance. The awareness and knowledge presented by the patient may have been in the form of apprehension, mental or physical breakdown, or poor relationships with the environment. The concept of balance required energy from both the APN and the patient and recognized the existence of many forms of energy. Dictionary.com [15] defined energy as the strength and vitality to sustain physical or mental work; therefore, the human being is a self-organizing open system and requires energy flow. Thus, energy must be present for balance to occur [4].

Walker and Avant [1] proposed that concept analyzers define the outcomes or consequences that must happen because of the concept's occurrence. The five consequences of the concept of balance were as follows: (a) equilibrium, (b) optimal function, (c) health, (d) wellness, and (e) optimal compensation. The Oxford Dictionary [16] defined balance in terms of equilibrium- "the state in which opposing forces or influences is balanced. This can be a state of physical balance or a calm state of mind" (para. 1). Balance also resulted in optimal function. Optimal function occurred when all components of the human being were in homeostasis; that is, the human being was operating in the best or most favorable fashion and engaged positively with his or her environment. In contrast, health appeared on a broader spectrum and was defined by the World Health Organization [17] as "a state of complete physical, mental, and social well-being, and not merely the absence of disease or infirmity" (para. 1). Wellness constituted a positive approach to living that influenced overall health; therefore, health and wellness cannot exist apart but must be experienced in tandem. When a human being has not been able to maintain optimal mental or physical function because of a loss of a limb or a birth deficit such as Down syndrome, for example, optimal compensation became an inappropriately defined goal for the human being, unless optimal compensation were defined as allowing the mental, physical, and psychic components of the human being to function at the best of his or her ability. With the best of ability component, the operational definition of optimal compensation enabled the human being to interact with his or her highest ability with his or her environment and within himself or herself, while considering deficits that may never resolve or goals that may never be achieved. When patients achieved the highest level of relationship with themselves and their environment, optimal compensation has occurred.

\section{Empirical Referents}

The final step of Walker and Avant's [1] concept analysis model required identifying empirical referents-ways the defining attributes of the concept in question could be measured. Although balance can be measured in the physical parts of the body, mental and spiritual balance comprised a much more complex concept to measure within the human being. The means for determining the occurrence of mental or spiritual balance has been through observation of behavior and patient report, but no tools or instruments were found to measure mental or spiritual balance.

APNs have directly measured balance within the body via laboratory test results, medical testing, and physical goal attainment. Such measures were only one component of the health and wellbeing of the human being-the physical. Measuring psychic and noetic balance has become the challenge for medical and nursing researchers. Researchers would need to create a scale for measuring balance within the noetic and spiritual components of the human being. As of this writing, APNs can measure balance in the noetic and psyche components of the human being by observing behaviors and subjective information provided by the patient. Such information was usually limited and generalized, however, such as the patient reported feeling good or well, had improved sleep patterns, had improved relationships with family and friends, and had developed a more peaceful relationship with his or her God. As an example, in bodytalk, Veltheim [2] offered various cases of emergency responders who used

Int J Nurs Clin Pract

ISSN: 2394-4978

IJNCP, an open access journal Volume 5. 2018. 281 
bodytalk techniques to prevent patients from going into shock and to slow down hemorrhaging. In the medical model, people thrived when balance and homeostasis were obtained in all body systems; that type of balance can be measured through medical testing.

\section{Implications for Nursing Practice and Nursing Research}

With a well-developed operational definition, balance was found to have a place in psychology, physiotherapy, and advanced practice nursing. APNs in all settings can use balance as a goal to help patients achieve optimal function, health, and wellness, or optimal compensation. Several practical implications were identified. The linear medical diagnostic approach to medicine has a limited optimal function by omitting an end goal of balance among the three components of the human being. Consequently, APNs utilizing the concept of balance as the backdrop of all end goals may have demonstrated great impact in improving health and wellness of patients in the modern-day healthcare system. When the three components of the human being were in balance, each component was able to interact and exchange energy with its environment and within itself. APNs applying the concept of balance may have learned to initiate a butterfly effect in healthcare systems as explained by the chaos theory [4].

Research implications appeared from this concept analysis on balance. A clear definition of balance required nursing scientists to seek to develop additional theoretical frameworks and assessment tools that APNs can use to achieve an optimal function for their patients and themselves.

\section{Discussion}

Figure 1 provides a framework for the concept of balance. The total human being is comprised of the nous, the physical, and the psychic components. For an optimal function to exist for the human being, a balance must occur among the nous, the physical, and the spiritual components. In addition, a relationship is involved with the being's interaction with his or her environment and the people within that environment. When the optimal balance is evident within the three areas of the human being, optimal function has occurred, and individuals achieving optimal function possess the ability to interact and grow in their environment. The self-observation methodology explained in CINT by Van Sell and Kalofissudis [4], and the utilization of the bodytalk techniques [2] may assist in the effectiveness of the care offered by the APN. Positive relationships must be established on multiple levels for the patient to reach balance and achieve optimal function. The APN's role is assisting the patients to move through their imbalance to arrive at equilibrium and optimal function using the attributes of the concept of balance; thus, health and wellness can be achieved.

\section{Competing Interests}

The authors, Byrne and Grizzard declare that they have no competing interests.

Dr. Van Sell declares she is co-author of the e-book The Evolving Essence of the Science of Nursing: The Complexity Integration Nursing Theory.

\section{Funding}

This article was published with support from Texas Woman's University Libraries' Open Access Fund.

\section{References}

1. Walker LO, Avant KC (2011) Strategies for Theory Construction in Nursing (5th edition), Upper Saddle River, NJ: Pearson Prentice Hall.

2. Veltheim J (2013) The Science and Philosophy of Bodytalk. Sarasota, FL: PaRama.

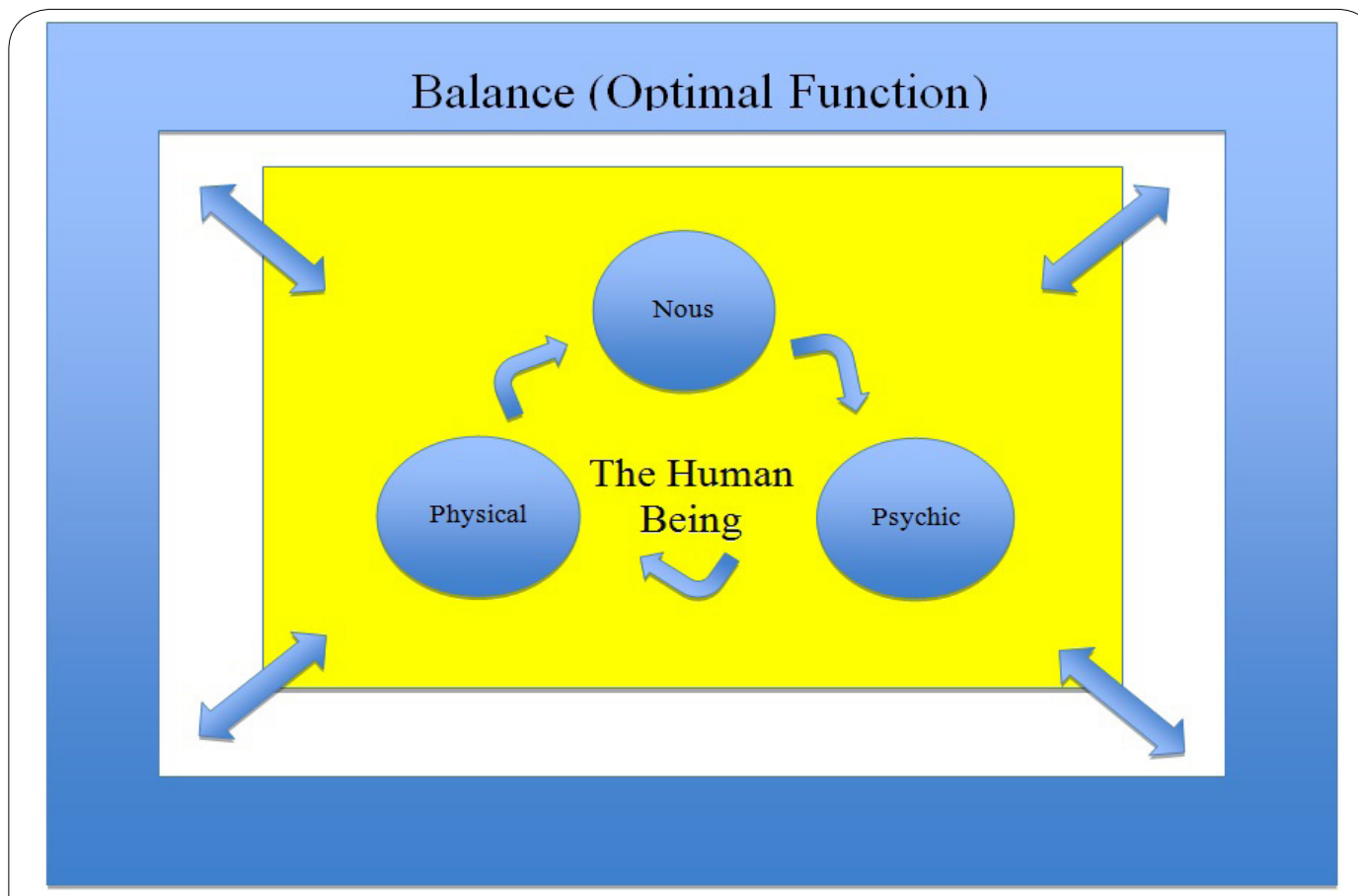

Figure 1: Concept model of Balance. 
3. Capra F (1984) The Turning Point: Science, Society, and the Rising Culture. New York, NY: Bantam.

4. Van Sell SL, Kalofissudis IA (2002) The evolving essence of the science of nursing: Complexity integration nursing theory. (E-book), Athens, Greece: ICU Web Journal.

5. Ragnarsdóttir M (1996) The concept of balance. Physiotherapy 82: 368375 .

6. Heider F (1958) The Psychology of Interpersonal Relations. New York, NY: Wiley.

7. Balance (2016) In Merriam-Webster online dictionary.

8. Balance (2016) In Cambridge Dictionary.

9. Balance (2016) In Oxford Dictionaries.

10. Tsuei JJ (1978) Eastern and Western approaches to medicine. West J Med 128: 551-557.

11. Woollacott MH (1993) Age-related changes in posture and movement. J Gerontol 48: 56-60.

12. Institute of Noetic Sciences (2016) What are the noetic sciences?.

13. Homeostasis (2016) Collins English Dictionary-Complete and Unabridged [12th digital ed.].

14. Cannon WB (1932) Homeostasis. The Wisdom of the Body. Norton, New York: Williams \& Wilkins.

15. Energy (2016) Dictionary.com Unabridged.

16. Equilibrium (2016) In Cambridge Dictionary.

17. World Health Organization (1948) WHO definition of health. 